\title{
Molecular evidence of Rickettsia felis infection in dogs from northern territory, Australia
}

\author{
Sze-Fui Hii ${ }^{1 *}$, Steven R Kopp ${ }^{1}$, Mary F Thompson ${ }^{1}$, Caroline A O'Leary ${ }^{1}$, Robert L Rees ${ }^{2}$ and Rebecca J Traub ${ }^{1}$
}

\begin{abstract}
The prevalence of spotted fever group rickettsial infection in dogs from a remote indigenous community in the Northern Territory (NT) was determined using molecular tools. Blood samples collected from 130 dogs in the community of Maningrida were subjected to a spotted fever group (SFG)-specific PCR targeting the ompB gene followed by a Rickettsia felis-specific PCR targeting the gltA gene of $R$. felis. Rickettsia felis ompB and gltA genes were amplified from the blood of 3 dogs. This study is the first report of $R$. felis infection in indigenous community dogs in NT.
\end{abstract}

\section{Introduction}

Rickettsioses are important emerging vector-borne diseases in humans [1], and some have been reported to infect dogs $[2,3]$. Rickettsioses that are purported to be endemic in Australia include murine typhus (Rickettsia typhi), Queensland tick typhus (Rickettsia australis), Flinders Island spotted fever (Rickettsia honei), scrub typhus (Orientia tsutsugamushi) and Q fever (Coxiella burnetti). Cat flea typhus or flea-borne spotted fever, caused by Ricketsia felis, which was first described in humans in the USA [4], is an emerging zoonosis that has been reported from throughout the world and was recently reported in a cluster of family members in Victoria, Australia [5].

The cat flea, Ctenocephalides felis, is a reservoir and biological vector of $R$. felis [6]. In Australia, R. felis DNA was first identified in fleas in 2006 [7]. Very recently, a molecular study in Australia detected R. felis in 9\% of 100 tested Southeast Queensland (SE QLD) pound dogs, suggesting that dogs may act as mammalian reservoir hosts for R. felis [8]. Given the close bond that exists between humans and canines, it is possible that dogs may be a potential source of $R$. felis infection for humans. Dogs are also important in indigenous community life, and it is therefore prudent to better understand the public health risks that may be associated with the human-animal bond in these communities. To this end, we sought to investigate the prevalence of spotted-fever group organisms in

\footnotetext{
* Correspondence: sze.hii@uqconnect.edu.au

'School of Veterinary Science, The University of Queensland, Gatton,

Queensland, 4343 Australia

Full list of author information is available at the end of the article
}

dogs from the indigenous community of Maningrida in the Northern Territory (NT), using PCR assays.

\section{Materials and methods}

Blood samples were collected from 130 dogs undergoing sterilisation facilitated by the Animal Management in Rural and Remote Indigenous Communities (AMRRIC) organisation in the indigenous community of Maningrida, NT. Sixty of these dogs were tested in September 2009 and 70 in September 2010. The sampled cohort of dogs was represented by 56 entire males and 69 entire females. Data on gender were unavailable for 5 dogs. One $\mathrm{mL}$ of whole blood was obtained from each dog by venipuncture, and the blood was immediately transferred to a QIAcard FTA $^{\circledR}$ Four Spots (Qiagen, Hilden, Germany) to facilitate preservation of DNA during transport.

DNA extraction from blood applied to FTA cards was carried out using the MasterPure ${ }^{\mathrm{TM}}$ DNA purification kit (Epicentre Biotechnologies, Madison, USA), following the protocol described by Abd Rani et al. [9].

All extracted DNA was subjected to a previously described PCR assay which amplifies a portion of the $o m p B$ gene in SFG rickettsiae [10]. DNA extracted from a Rickettsia conorii culture obtained from the Australian Rickettsial Reference Laboratory was used as a positive control, whilst nuclease- free water (NFW) was used as a negative control. Blood samples found to be positive for SFG rickettsial DNA were further subjected to a speciesspecific nested PCR for $R$. felis, which amplified the gltA gene (Table 1). Rickettsia felis specific primers were designed by aligning glt A sequences retrieved from 
Table 1 Sequences and primer sets for the amplification of a partial region of the ompB gene of SFG rickettsiae and $g / t A$ gene of $R$. felis

\begin{tabular}{llc}
\hline Gene & Primer name and sequence $\left.\mathbf{( 5}^{\prime} \mathbf{- 3} \mathbf{3}^{\prime}\right)$ & Product size \\
\hline ompB & $\begin{array}{l}\text { ompB-F (CGACGTTAACGGTTCTCATTCT) } \\
\text { ompB-R (ACCGGTTTCTTGTAGTTTCGTC) }\end{array}$ & $252 \mathrm{bp} \mathrm{[10]}$ \\
\hline gltA & gltA-F1 (GCAAGTATTGGTGAGGATGTAATC) & $654 \mathrm{bp}$ \\
& gltA-R1 (CTGCGGCACGTGGGTCATAG) & \\
& gltA-F2 (GCGACATCGAGGATATGACAT) & \\
& gltA-R2 (GGAATATTCTCAGAACTACCG) & \\
\hline
\end{tabular}

GenBank of closely related rickettsial species (R. felis, [GenBank: CP000053]; R. australis, [GenBank: U59718]; Rickettsia_rickettsii, [GenBank: U59729]; R. typhi, [GenBank: U59714]) using CLUSTALW program http://www. genome.jp/tools/clustalw/. Nested PCR primers were manually designed by selecting a region specific to $R$. felis (Table 1). However, the potential cross-reaction of this newly designed PCR was not tested with other Rickettsia spp. This PCR that was developed relies on confirming diagnosis by DNA sequencing to ensure there is no cross reactivity with closely related organisms.

Primary PCR amplification of the gltA gene of $R$. felis was performed in a $25 \mu \mathrm{l}$ reaction mixture containing $2 \mu \mathrm{l}$ of DNA, $5 \mu \mathrm{l} 5 \times$ PCR buffer, $200 \mu \mathrm{mol} / \mathrm{L}$ dNTP, $2.0 \mathrm{mmol} / \mathrm{L} \mathrm{MgCl}_{2}, 0.5$ units of GoTaq polymerase (Promega, Madison, WI, USA), 10 pmol of each forward and reverse primer made to the final volume with NFW. Two $\mu \mathrm{l}$ of distilled water and $R$. felis DNA isolated from an infected cat flea were used as negative and positive control, respectively. PCR cycling conditions comprised an initial activation step at $95^{\circ} \mathrm{C}$ for $2 \mathrm{~min}$, followed by 40 cycles of $95^{\circ} \mathrm{C}$ for $45 \mathrm{~s}, 63^{\circ} \mathrm{C}$ for $30 \mathrm{~s}$ and $72^{\circ} \mathrm{C}$ for $45 \mathrm{~s}$ with a final extension step of $72^{\circ} \mathrm{C}$ for $7 \mathrm{~min}$. The secondary round of PCR amplification was performed as for the primary round except that the annealing temperature was $59^{\circ} \mathrm{C}$.

All amplified PCR products of both SFG rickettsial and $R$. felis-specific PCR were visualised via transillumination on $1.6 \%$ agarose gel stained with $\mathrm{SYBR}^{\circledR}$ Safe (Invitrogen, Eugene, USA) DNA gel stain. All PCR products of the correct size were purified using QIAquick ${ }^{\mathrm{TM}}$ PCR Purification Kit (Qiagen, Hilden, Germany) according to manufacturer's protocol and subjected to DNA sequencing using both forward and reverse primers. DNA sequences were assessed for homology with those in GenBank using the NCBI Blast program http://blast.ncbi.nlm.nih.gov/Blast.cgi.

This project was approved by the University of Queensland Animal Ethics Committee.

\section{Results}

Of the total 130 tested samples, three (2.3\%) were SFG rickettsial PCR-positive and DNA sequences were $>99 \%$ homologous with $R$. felis omp B gene [GenBank: GQ385243]. Subsequent $R$. felis-specific nested PCR determined all three SFG positive dogs to harbour $R$. felis DNA. Sequences were $100 \%$ homologous to the $R$. felis gltA gene [GenBank: CP000053].

\section{Discussion}

This is the first study to report the presence of $R$. felis infection in indigenous community dogs in the NT. In Australia, $R$. felis was first identified in fleas collected from dogs and cats in Western Australia in 2006 [7]. Recently, $19.8 \%$ of fleas collected from cats in Brisbane, Sydney and Melbourne [11] and 9\% of pound dogs in SE QLD in Australia were reported to harbour $R$. felis DNA as identified by PCR [8]. Cat flea typhus was also reported in a cluster of human patients in Victoria [5]. The findings of these studies supported the presence of a peridomestic cycle and wide geographical distribution for this pathogen in Australia.

In the previous molecular study, the infection of R. felis in pound dogs in SE QLD was confirmed by PCR assay targeting only the $о m p \mathrm{~B}$ gene and confirmed by phylogenetic analysis. In this study, the gltA gene of $R$. felis in dogs' blood was amplified in addition to the $\operatorname{omp} \mathrm{B}$ gene by a novel $R$. felis-specific nested PCR. This study strengthens the evidence for dogs harbouring active rickettsaemias of this emerging zoonotic pathogen, and supports the role of dogs as important reservoir hosts. This finding was also supported by a study reporting concurrent $R$. felis infections in a PCR-positive dog and its infected owners in Spain [12].

In this study, the flea infestation in indigenous community dogs was not evaluated in terms of flea species and burden. However, the cat flea, C. felis, is the most common flea infesting dogs in Australia $[7,13]$. These indigenous community dogs lead a semi-domesticated life. They are mostly poorly cared for and often infested by ectoparasites. Hence, it is likely that the dogs in this study were infested with fleas.

The prevalence of $R$. felis infection in indigenous community dogs $(2.3 \%)$ is lower than those reported in pound dogs in SE QLD (9\%) [8]. The transportation of blood using FTA cards and different DNA extraction technique may have partially affected the prevalence detected in indigenous community dogs. This is supported by studies showing amplification of DNA extracted from whole blood is more sensitive and reliable than filter paper-based technologies $[14,15]$. It should also be noted that neither study was particularly comprehensive with respect to sampling across different sites in each region, hence caution is required in making detailed comparisons with respect to prevalence. In this study, all dogs also appeared physically healthy, a common feature that is usually a characteristic of reservoir hosts, however further study is needed to determine the pathogenesis and pathogenic potential of $R$. felis infections in dogs. 


\section{Conclusion}

This study further supports the potential role of dogs as reservoir hosts of $R$. felis and suggests that this pathogen has a wide geographical distribution in Australia.

\section{Acknowledgements}

The authors thank Dr Ted Donelan, the president of Animal Management in Rural and Remote Indigenous Communities (AMRRIC), Sacha Woodburn and Natalie Noble, veterinary students from the University of Queensland for their assistance with fieldwork in Maningrida, and Australian Rickettsial Reference Laboratory for the positive control of rickettsial PCR. This study was funded by Bayer Animal Health Australia and the Centre for Companion Animal Health, School of Veterinary Science, The University of Queensland.

\section{Author details}

'School of Veterinary Science, The University of Queensland, Gatton, Queensland, 4343 Australia. ${ }^{2}$ Bayer Animal Health Tingalpa, Brisbane, Queensland, 4343 Australia.

\section{Authors' contributions}

SFH carried out the laboratory work, data analysis, intellectual interpretation and writing of the manuscript. RJT designed the study project, supervised the study, and was involved in intellectual interpretation and critical revision of the manuscript for publication. SRK supervised the study and was involved in intellectual interpretation and critical revision of the manuscript for publication. MFT, CAO and RLR revised the article critically for important intellectual content. All authors read and approved the final manuscript.

\section{Competing interests}

The authors declare that they have no competing interests.

Received: 15 July 2011 Accepted: 11 October 2011

Published: 11 October 2011

\section{References}

1. Parola P, Davoust B, Raoult D: Tick- and flea-borne rickettsial emerging zoonoses. Veterinary Research 2005, 36:469-492.

2. Gasser AM, Birkenheuer AJ, Breitschwerdt EB: Canine Rocky Mountain spotted fever: A retrospective study of 30 cases. J Am Anim Hosp Assoc 2001, 37:41-48.

3. Solano-Gallego L, Kidd L, Trotta M, Di Marco M, Caldin M, Furlanello T, Breitschwerdt E: Febrile illness associated with Rickettsia conorii infection in dogs from Sicily. Emerg Infect Dis 2006, 12:1985-1988.

4. Schriefer ME, Sacci JB, Dumler JS, Bullen MG, Azad AF: Identification of a novel rickettsial infection in a patient diagnosed with murine typhus. J Clin Microbiol 1994, 32:949-954.

5. Williams M, Izzard L, Graves SR, Stenos J, Kelly JJ: First probable Australian cases of human infection with Rickettsia felis (cat-flea typhus). Med J Australia 2010, 194:41-43.

6. Reif KE, Macaluso KR: Ecology of Rickettsia felis: A Review. J Med Entomol 2009, 46:723-736.

7. Schloderer D, Owen H, Clark P, Stenos J, Fenwick SG: Rickettsia felis in fleas, Western Australia. Emerg Infect Dis 2006, 12:841-843.

8. Hii SF, Kopp SR, Abdad MY, Thompson MF, O'Leary CA, Rees RL, Traub RJ: Molecular Evidence Supports the Role of Dogs as Potential Reservoirs for Rickettsia felis. Vector Borne Zoonotic Dis 2011

9. Abd Rani PAM, Irwin PJ, Gatne M, Coleman GT, McInnes LM, Traub RJ: A survey of canine filarial diseases of veterinary and public health significance in India. Parasite Vectors 2010, 3:30.

10. Paris DH, Blacksell SD, Stenos J, Graves SR, Unsworth NB, Phetsouvanh R, Newton PN, Day NPJ: Real-time multiplex PCR assay for detection and differentiation of rickettsiae and orientiae. Trans $R$ Soc Trop Med Hyg 2008, 102:186-193.

11. Barrs VR, Beatty JA, Wilson BJ, Evans N, Gowan R, Baral RM, Lingard AE, Perkovic G, Hawley JR, Lappin MR: Prevalence of Bartonella species, Rickettsia felis, haemoplasmas and the Ehrlichia group in the blood of cats and fleas in eastern Australia. Aust Vet J 2010, 88:160-165.
12. Oteo JA, Portillo A, Santibanez S, Blanco JR, Perez-Martinez L, Ibarra V: Cluster of cases of human Rickettsia felis infection from Southern Europe (Spain) diagnosed by PCR. J Clin Microbiol 2006, 44:2669-2671.

13. Slapeta J, King J, McDonell D, Malik R, Homer D, Hannan P, Emery D: The cat flea (Ctenocephalides $f$. felis) is the dominant flea on domestic dogs and cats in Australian veterinary practices. Vet Parasitol 2011.

14. Jefferies R, Ryan UM, Irwin PJ: PCR-RFLP for the detection and differentiation of the canine piroplasm species and its use with filter paper-based technologies. Vet Parasitol 2007, 144:20-27.

15. Zhong KJY, Salas CJ, Shafer R, Gubanov A, Gasser RA, Magill AJ, Forney JR, Kain KC: Comparison of IsoCode STIX and FTA gene guard collection matrices as whole-blood storage and processing devices for diagnosis of malaria by PCR. J Clin Microbiol 2001, 39:1195-1196.

doi:10.1186/1756-3305-4-198

Cite this article as: Hii et al:: Molecular evidence of Rickettsia felis infection in dogs from northern territory, Australia. Parasites \& Vectors 2011 4:198

\section{Submit your next manuscript to BioMed Central and take full advantage of:}

- Convenient online submission

- Thorough peer review

- No space constraints or color figure charges

- Immediate publication on acceptance

- Inclusion in PubMed, CAS, Scopus and Google Scholar

- Research which is freely available for redistribution

Submit your manuscript at www.biomedcentral.com/submit
C Biomed Central 